\title{
Epidemiological Survey of Toxoplasmosis among Aborted Women in Garmian district, Kurdistan Region, Iraq
}

\author{
Salar Ibrahim Ali \\ Community Health Department \\ Technical College of Health \\ Sulaimani Polytechnic University \\ Sulaimani, Iraq \\ salaribrahimali@yahoo.it
}

\begin{abstract}
Toxoplasmosis is a zoonotic infection that caused by an obligated intracellular parasite Toxoplasma gondii of many types of tissues, including nervous, muscular and intestinal epithelial tissue. Congenital toxoplasmosis is most severe condition when occurs in early period of pregnancy. The main aim of this study is to determine prevalence of toxoplasmosis among aborted women in Garmian region by using both Latex Agglutination Test (LAT) and Enzyme Linked Immunosorbent Assay (ELISA). The study was carried out in Kalar General Hospital to detect Toxoplasma antibodies among 350 samples, in which 250 samples were from aborted women and 100 samples were from normal birth women as a control. Participants' age was range from $<18$ to $>35$ years old. The data were collected form $15^{\text {th }}$ January 2009 to $25^{\text {th }}$ June 2010 by using a special questionnaire form to obtain full information from each participant. For statistical analysis of the data, Statistical Package for Social Sciences (SPSS) version 22 was used. The study showed that (112) cases out of 250 were seropositive for Toxoplasma gondii by using LAT, (65) cases for IgG and (50) cases for IgM by using ELISA. In the abortion group, it showed (87) cases out of 150 were seropositive by using LAT, (51) cases for IgG and (40) cases for IgM (26.6\%), whereas in normal birth group (control), it showed (25) case out of 100 were seropositive by using LAT, (14) case for IgG and (10) case for IgM by using ELISA. A High seropositivity percentage was recorded among housewives (35.2\%) than teachers and employees (29.4\%), (28.5\%) respectively. Furthermore, a higher percentage of Toxoplasma seropositivity was recorded in rural area than urban area. The aborted women who were in contact with soil showed the higher rate of Toxoplasma seropositivity (38.7\%) than those were not in contact with soil (25\%). This study concluded that the prevalence of toxoplasmosis was higher in Garmian region and especially among those women who have lower education level and who live in rural areas.
\end{abstract}

Keywords: Epidemiological Survey, Toxoplasmosis, Aborted women, Garmian, Immunological tests.

\section{INTRODUCTION}

Toxoplasmosis is a zoonotic disease caused by an obligatory intracellular protozoan parasite Toxoplasma gondii, which appears to have broad host specificity. Cats and wild Felines are the only definitive hosts while all other warm-blooded animals including humans are intermediate hosts [1]. Infection is acquired by ingestion of viable tissue cysts in meat or oocysts excreted by cats that contaminate food or water [2]. Congenital transmission may occur when an uninfected mother acquires primary infection during pregnancy [1]; the infection may also be transmitted through blood or leukocyte transfusion [3], or organ transplantation [4, 5].

Toxoplasmosis infection in immunocompetent adults and adolescent are generally asymptomatic, but symptoms may include mild malaise, lethargy and lymphadenopathy [6]. When the disease occurs during pregnancy $20-30 \%$ of cases terminate either with spontaneous abortion, stillbirth and premature delivery or birth of infected baby with undesirable sequels later in life as blindness and deafness; it is considered as a main infection which causes blindness all over the world [7]. The gestational age at which the infection is contracted is a key variable affecting the clinical fetal outcome ([8]. T. gondii can also cause severe encephalitis via acute infection or reactivation of latent infection among immunosuppressed patients, including those with acquired immunodeficiency syndrome (AIDS), those with immunosuppressive cancer, and transplant recipients on immunosuppressive drugs (e.g. Cyclosporine). Toxoplasmosis is the most frequent severe neurological infection among persons with AIDS [9]. The risk factors that are often associated with acute infection in pregnant women were eating raw or undercooked meat and soil contact. Weaker associations were observed for tasting raw meat during preparation of meals, eating salami, drinking unpasteurized milk and animal contact $[10,2]$.

The aim of this study is, to determine epidemiological survey of toxoplasmosis among aborted women in 
Garmian region by using serological method, such as Enzyme-linked Immunosorbent Assay (ELISA) and to investigate the effect of some factors such as age, job style, soil contact and obstetrical history including (number of pregnancy, type of abortion, gestational age), educational back ground, residence area on the incidence of toxoplasmosis.

\section{METHODS AND MATERIALS}

The study was performed in Garmian area, Iraqi Kurdistan Region. The sample size was 250 samples, which divided into normal birth women (100 samples) and aborted women (150 samples); the study was started from $1^{\text {st }}$ November 2016 till June of 2017 at Kalar General Hospital, in addition to private clinics in Garmian area. Data were collected from all aborted and normal birthed women by interviews using a specially designed, pretested questionnaire. Interviews were conducted face to face at the Kalar General Hospital and private clinic by staff nurses or medical technologist. Women firstly asked about age, place of residence (urban or rural) and occupation, obstetrical history (total number of pregnancy, stillbirths, abortions and live birth).

The blood samples were collected after cleaning the area by using denaturized $70 \%$ medical spirit. Five ml of venous blood was taken in a $5 \mathrm{ml}$ tubes size disposable syringe the transferred to $10 \mathrm{ml}$ disposable sterile test tubes. The blood was then centrifuged at $3000 \mathrm{rpm}$ for 5 minutes then serum samples were aspirated by using automatic micropipette transferred to $3 \mathrm{ml}$ sized micro test tube with screw cap, each serum was labeled and numbered before keeping at 4-8 $\mathrm{C}^{\circ}$ for 24-48 hrs. If longer periods of storage are required sera kept in deep freeze at $-20 \mathrm{C}^{\circ}$ for a late serological testing. All isolated sera were tested serologically for detection of specific antibodies to $T$. gondii by the using of LAT and IgM, IgG by ELISA technique.

Analysis of data was performed by using Statistical Package for Social Science (SPSS) version 22.0. Chisquare test was applied to find association between categorical variables. Continues variables were checked using t-test. $\mathrm{P}$ values $\mathrm{p} \leq 0.05$ were considered statistically significant.

\section{RESULTS}

\section{Prevalence of Toxoplasma gondii seropositivity using LAT}

The results in (Table 1) show the prevalence of Toxoplasma seropositivity using LAT. In 250 samples, there were $112(44.8 \%)$ seropositive in overall groups; in normal birth group, there were 25(25\%) seropositive cases out of 100 -screened samples and in abortion group from 150 samples 87(58\%) were seropositive. The statistical analysis appears significant difference at $\mathrm{P}<$ 0.01 .
Table 1: Prevalence of Toxoplasma seropositivity using LAT.

\begin{tabular}{|c|c|c|c|}
\hline Test samples & No. Examined & No. Positive & No. Negative \\
\hline Normal birth & 100 & $\begin{array}{c}25 \\
(25 \%)\end{array}$ & 75 \\
\hline Abortion & 150 & $\begin{array}{c}87 \\
(58 \%)\end{array}$ & 63 \\
\hline Total & 250 & $112(44.8 \%)$ & 138 \\
\hline
\end{tabular}

\section{Prevalence of Toxoplasma gondii seropositivity using ELISA technique.}

The results in (Table 2) show that the prevalence of $T$. gondii seropositivity using ELISA technique, screening for IgG type antibodies specific to $T$. gondii in 250 samples, there were 65(26\%) seropositive in overall groups; in normal birth group there were 14(14\%) seropositive cases out of 100-screened samples and in abortion group from 150 samples 51(34\%) were seropositive .The statistical analysis appears significant difference at $\mathrm{P}<0.01$, while screening for IgM type antibodies specific to $T$. gondii in 250 samples, there were $50(20 \%)$ seropositive in overall groups; in normal birth group there were $10(10 \%)$ seropositive cases out of 100 -screened samples and in abortion group from 150 samples $40(26.6 \%)$ were seropositive .The statistical analysis appears a significant difference at $\mathrm{P}<0.01$.

Table 2: Prevalence of Toxoplasma gondii seropositivity using ELISA technique.

\begin{tabular}{|c|c|c|c|c|c|}
\hline \multirow[t]{2}{*}{ Test samples } & \multirow[t]{2}{*}{ Total No. } & \multicolumn{2}{|c|}{$\begin{array}{c}\text { IgG } \\
\text { ELISA }\end{array}$} & IgM I & ELISA \\
\hline & & $+v e$ & -ve & $+v e$ & -ve \\
\hline Normal birth & 100 & $\begin{array}{c}14 \\
(14 \%)\end{array}$ & 86 & $\begin{array}{c}10 \\
(10 \%)\end{array}$ & 90 \\
\hline Abortion & 150 & $\begin{array}{l}51 \\
(34 \%) \\
\end{array}$ & 99 & $\begin{array}{c}40 \\
(26.6 \%) \\
\end{array}$ & 110 \\
\hline Total & 250 & $65(26 \%)$ & 185 & $50(20 \%)$ & 200 \\
\hline
\end{tabular}

Seropositivity of Anti-Toxoplasma by ELISA technique and LAT in relation to gestational age of aborted women

The results in (Table 3) show that the distribution of Toxoplasma seropositivity using ELISA technique and LAT in relation to gestational age of aborted women. Screening for IgG type antibodies specific to T. gondii. In 150 samples, there were 51(34\%) seropositive cases out of 150-screened samples, the highest seropositivity in second trimester were $17(45.9 \%)$ out of 37 samples, followed by first trimester were 33(33.3\%) out of 37 samples and lowest seropositivity in third trimester were $1(7.1 \%)$ out of 14 samples. Screening for IgM type antibodies specific to $T$. gondii. In 150 samples, there were $40(26.6 \%)$ seropositive cases out of 150 -screened samples, the highest seropositivity in second trimester were $11(29.7 \%)$ out of 37 samples, followed by first trimester were 29(29.2\%) out of 37 samples and lowest seropositivity in third trimester were $0(0 \%)$ out of 14 samples. While in LAT screening for antibodies specific to T. gondii. In 150 samples, there were 87(58\%) seropositive cases out of 150 -screened samples, the 
highest seropositivity in first trimester were 66 (66.6\%) out of 120 samples, followed by second trimester were 19(51.3\%) out of 37 samples and lower seropositivity in third trimester were 2 (14.2\%) out of 14 samples. Statistical analysis appears significant difference at $\mathrm{P}<$ 0.01 .

Table 3: Seropositivity of Anti-Toxoplasma by ELISA technique and LAT in relation to gestational age of aborted women.

\begin{tabular}{|c|c|c|c|c|c|c|c|}
\hline \multirow{3}{*}{$\begin{array}{c}\text { Gestational } \\
\text { Age }\end{array}$} & \multirow{3}{*}{\begin{tabular}{|c|} 
Total \\
No.
\end{tabular}} & \multicolumn{4}{|c|}{ ELISA } & \multirow{2}{*}{\multicolumn{2}{|c|}{ LAT }} \\
\hline & & \multicolumn{2}{|l|}{ IgG } & \multicolumn{2}{|l|}{ IgM } & & \\
\hline & & tve & -ve & tve & -ve & tve & -ve \\
\hline $1^{\text {st }}$ trimester & 99 & $33(33.3 \%)$ & 66 & $29(29.2 \%)$ & 70 & $66(66.6 \%)$ & 33 \\
\hline $2^{m}$ trimester & 37 & $17(45.9 \%)$ & 20 & $11(29.7 \%)$ & 26 & $19(51.3 \%)$ & 18 \\
\hline $3^{\text {td }}$ trimester & 14 & $1(7.1 \%)$ & 13 & $0(0 \%)$ & 14 & $2(14.2 \%)$ & 12 \\
\hline Total & 150 & 51 & 99 & 40 & 110 & $87(58 \%)$ & 63 \\
\hline
\end{tabular}

Table (4-8) Shows the distribution of Toxoplasma seropositivity using ELISA technique and LAT in relation to gestational age of control group. Screening for IgG type antibodies specific to T. gondii, In 100 samples, there were $14(14 \%)$ seropositive cases out of 100 -screened samples, the highest seropositivity in third trimester were $14(14 \%)$ out of 100 samples and lowest seropositivity in both first and second trimester were 0 (0\%) out of 0 samples. Screening for IgM type antibodies specific to $T$. gondii, In 100 samples, there were $10(10 \%)$ seropositive cases out of 100 -screened samples, the highest seropositivity in were third trimester $10(10 \%)$ out of 100 samples and lower seropositivity in both first and second trimester were $0(0$ $\%)$ out of 0 samples. While in LAT screening for antibodies specific to T. gondii, In 100 samples, there were $25(25 \%)$ seropositive cases out of 100 -screened samples, the highest seropositivity in third trimester were 25 (25\%) out of 100 samples and lower seropositivity in both first and second trimester were 0 (0\%) out of 0 samples. Statistical analysis appears no significant difference at $\mathrm{P}<0.05$.

Table 4: Seropositivity of Anti-Toxoplasma ELISA technique and LAT in relation to gestational

\begin{tabular}{|c|c|c|c|c|c|c|c|}
\hline age & \multicolumn{2}{|c|}{ of } & \multicolumn{3}{|c|}{ control } & \multicolumn{2}{|c|}{ group. } \\
\hline \multirow{3}{*}{$\begin{array}{c}\text { Gestational } \\
\text { Age }\end{array}$} & \multirow{3}{*}{$\begin{array}{l}\text { Total } \\
\text { No. }\end{array}$} & \multicolumn{4}{|c|}{ ELISA } & \multicolumn{2}{|c|}{ LAT } \\
\hline & & IgC & & Ig & & & \\
\hline & & tye & -ve & tye & -ve & tye & -ve \\
\hline $1^{\text {st }}$ trimester & 0 & $0(0 \%)$ & 0 & $0(0 \%)$ & 0 & $0(0 \%)$ & 0 \\
\hline $2^{\text {nd }}$ trimester & 0 & $0(0 \%)$ & 0 & $0(0 \%)$ & 0 & $0(0 \%)$ & 0 \\
\hline $3^{\text {rd }}$ trimester & 100 & $14(14 \%)$ & 86 & $10(10 \%)$ & 90 & $25(25 \%)$ & 75 \\
\hline Total & 100 & 14 & 86 & 10 & 90 & 25 & 75 \\
\hline
\end{tabular}

Seropositivity of Anti-Toxoplasma by ELISA technique in relation to residence area of aborted women.

The results in (Table 5) show that the distribution of Toxoplasma seropositivity using ELISA technique in relation to residence area of control group. Screening for IgG type antibodies specific to $T$. gondii. In 100 samples, there were $14(14 \%)$ seropositive cases out of
100 -screened samples, high seropositivity in urban area were 8 (12.5\%) out of 64 samples and low seropositivity in rural area were $6(16.6 \%)$ out of 36 samples. Screening for IgM type antibodies specific to T. gondii. In 100 samples, there were $10(10 \%)$ seropositive cases out of 100-screened samples, high seropositivity in urban area were 6(9.3\%) out of 48 samples and low seropositivity in rural area were $4(11.1 \%)$ out of 36 samples, while in LAT screening for antibodies specific to T. gondii. In 100 samples, there were 25(25\%) seropositive cases out of 100-screened samples, high seropositivity in rural area were 10 (27\%) out of 36 samples and low seropositivity in urban area were 15 (23.4\%) out of 64 samples. Statistical analysis appears no significant difference at $\mathrm{P}<0.05$.

Table 5: Seropositivity of Anti-Toxoplasma by ELISA technique in relation to residence area of aborted women.

\begin{tabular}{|c|c|c|c|c|c|}
\hline \multirow{3}{*}{$\begin{array}{c}\text { Residence } \\
\text { Area }\end{array}$} & \multirow{3}{*}{$\begin{array}{l}\text { Total } \\
\text { No. }\end{array}$} & \multicolumn{4}{|c|}{ ELISA } \\
\hline & & \multicolumn{2}{|c|}{ IgG } & \multicolumn{2}{|c|}{ IgM } \\
\hline & & tve & -ve & tve & -ve \\
\hline Urban area & 83 & $\begin{array}{c}27 \\
(32.5 \%)\end{array}$ & 52 & $\begin{array}{c}21 \\
(25.3 \%)\end{array}$ & 59 \\
\hline Rural area & 67 & $\begin{array}{c}24 \\
(35.8 \%)\end{array}$ & 47 & $\begin{array}{c}19 \\
(28.3 \%)\end{array}$ & 51 \\
\hline Total & 150 & $51(34 \%)$ & 99 & $40(26.6 \%)$ & 110 \\
\hline
\end{tabular}

The results in (Table 6) show that the distribution of Toxoplasma seropositivity using ELISA technique in relation to residence area of aborted women. Screening for IgG type antibodies specific to $T$. gondii. In 150 samples, there were $51(34 \%)$ seropositive cases out of 150 -screened samples, high seropositivity in urban area were 31(37.3\%) out of 83 samples and low seropositivity in rural area were $20(29.8 \%)$ out of 67 samples. Screening for IgM type antibodies specific to T. gondii. In 150 samples, there were 40(26.6\%) seropositive cases out of 150-screened samples, high seropositivity in urban area were $21(25.3 \%)$ out of 83 samples and low seropositivity in rural area were 19 (28.3\%) out of 67 samples. Statistical analysis appears significant difference at $\mathrm{P}<0.01$.

Table 6: Seropositivity of Anti-Toxoplasma by ELISA technique in relation to residence area of control women.

\begin{tabular}{|c|c|c|c||c|l||}
\hline \multirow{2}{*}{$\begin{array}{c}\text { Residence } \\
\text { Area }\end{array}$} & \multirow{2}{*}{$\begin{array}{c}\text { Notal } \\
\text { No. }\end{array}$} & \multicolumn{4}{|c|}{ ELISA } \\
\cline { 2 - 6 } & & \multicolumn{2}{|c|}{ IgG } & \multicolumn{2}{|c|}{ IgM } \\
\hline \hline $\begin{array}{c}\text { Urban } \\
\text { area }\end{array}$ & 64 & 8 & 55 & 6 & 57 \\
\hline Rural area & 36 & 6 & 31 & 4 & 33 \\
& & $(12.5 \%)$ & & $(9.3 \%)$ & \\
\hline \hline Total & 100 & $14(14 \%)$ & 86 & $10(10 \%)$ & 90 \\
\hline
\end{tabular}


Seropositivity of Anti-Toxoplasma by ELISA technique and LAT in relation to cat contact of control women.

Table (4-20) Show the distribution of Toxoplasma seropositivity using ELISA technique and LAT in relation to cat contact of control group. Screening for IgG type antibodies specific to $T$. gondii. In 100 samples, there were $14(14 \%)$ seropositive cases out of 100-screened samples, higher seropositivity in cat contact were 11 (16.1\%) out of 68 samples and lower seropositivity in non-cat contact were $3(9.3 \%)$ out of 32 samples. Screening for IgM type antibodies specific to Toxoplasma gondii. In 100 samples, there were 10 (10\%) seropositive cases out of 100-screened samples, higher seropositivity in cat contact were $8(11.7 \%)$ out of 68 samples and lower seropositivity in non-cat contact were $2(6.2 \%)$ out of 32 samples. While in LAT screening for antibodies specific to T. gondii. In 100 samples, there were 25(25\%) seropositive cases out of 100 -screened samples, higher seropositivity in cat contact were $20(29.4 \%)$ out of 36 samples and lower seropositivity in non-cat contact were 5 (15.6\%) out of 32 samples. Statistical analysis appears no significant difference at $\mathrm{P}<0.05$.

Table 7: Seropositivity of Anti-Toxoplasma by ELISA technique and LAT in relation to cat contact of aborting women.

\begin{tabular}{|l|c|c|c|c||c|}
\hline \multirow{2}{*}{$\begin{array}{c}\text { Residence } \\
\text { Area }\end{array}$} & \multirow{2}{*}{$\begin{array}{c}\text { Notal } \\
\text { No. }\end{array}$} & \multicolumn{4}{|c|}{ ILISA } \\
\cline { 2 - 6 } & & + ve & - ve & tve & -ve \\
\hline Urban area & 83 & $\begin{array}{c}27 \\
(32.5 \%)\end{array}$ & 52 & $\begin{array}{c}21 \\
(25.3 \%)\end{array}$ & 59 \\
\hline Rural area & 67 & $\begin{array}{c}24 \\
(35.8 \%)\end{array}$ & 47 & $\begin{array}{c}19 \\
(28.3 \%)\end{array}$ & 51 \\
\hline Total & 150 & $51(34 \%)$ & 99 & $40(26.6 \%)$ & 110 \\
\hline \hline
\end{tabular}

Table (4-19) Shows the distribution of Toxoplasma seropositivity using ELISA technique and LAT in relation to cat contact of aborted women. Screening for IgG type antibodies specific to Toxoplasma gondii. In 150 samples, there were 51(34\%) seropositive cases out of 150-screened samples, high seropositivity in cat contact were $38(38.7 \%)$ out of 98 samples and low seropositivity in non-cat contact were 13(25\%) out of 52 samples. Screening for IgM type antibodies specific to Toxoplasma gondii. In 150 samples, there were 40(26.6\%) seropositive cases out of 150-screened samples, high seropositivity in non-cat contact were $14(26.9 \%)$ out of 52 samples and low seropositivity in cat contact were 26 (26.5\%) out of 98 samples, while in LAT screening for antibodies specific to T. gondii. In 150 samples, there were 87(57.9\%) seropositive cases out of 150-screened samples, high seropositivity in cat contact were $68(69.3 \%)$ out of 98 samples and low seropositivity in non-cat contact were 19 (36.5\%) out of 52 samples. Statistical analysis appears significant difference at $\mathrm{P}<0.01$.
Table 8: Seropositivity of Anti-Toxoplasma by ELISA technique and LAT in relation to cat contact of control women.

\begin{tabular}{|c|c|c|c|c|c|}
\hline \multirow{3}{*}{$\begin{array}{c}\text { Residence } \\
\text { Area }\end{array}$} & \multirow{3}{*}{$\begin{array}{l}\text { Total } \\
\text { No. }\end{array}$} & \multicolumn{4}{|c|}{ ELISA } \\
\hline & & \multicolumn{2}{|c|}{ IgG } & \multicolumn{2}{|c|}{$\operatorname{IgM}$} \\
\hline & & tve & $-v e$ & tve & -ve \\
\hline $\begin{array}{l}\text { Urban } \\
\text { area }\end{array}$ & 64 & $\begin{array}{c}8 \\
(12.5 \%)\end{array}$ & 55 & $\begin{array}{c}6 \\
(9.3 \%)\end{array}$ & 57 \\
\hline Rural area & 36 & $\begin{array}{c}6 \\
(16.6 \%)\end{array}$ & 31 & $\begin{array}{c}4 \\
(11.1 \%)\end{array}$ & 33 \\
\hline Total & 100 & $14(14 \%)$ & 86 & $10(10 \%)$ & 90 \\
\hline
\end{tabular}

\section{DISCUSSION}

Toxoplasmosis has been established that has a worldwide distribution in human and other warmblooded vertebrates but the frequency of the infection varies from one country to another and also in different part of a given country [11]. One half billion human infection is a conservative estimate [12].

The current study is the first study performed in Garmian district to determine the seroprevalence of $T$. gondii infection between normal birth and aborted women groups. The seroprevalence of toxoplasmosis in the present study was $58 \%$ of aborted women, whereas $25 \%$ of normal birth by using LAT test and 34\% for IgG and $26.6 \%$ for IgM in aborted women, whereas $14 \%$ for IgG and $10 \%$ for IgM in normal birth women by using ELISA technique. These results in consistence with those of [13] in Diala province, Al- Timimi, (2004) in Baghdad [14] and Fatohi, (1985) in Musol city [15], Al-Attar, (2000) in Kirkuk [16], showed that the seroprevalence of toxoplasmosis were $54.0 \%, 55.26 \%, 52.6 \%$ and $42.6 \%$ respectively. But the results of the present study are not in agreement with which showed of some studies in Iraqi provinces, as in Baghdad showed that the seroprevalence of toxoplasmosis, in the first study was $12.3 \%$ by using skin test and in the second study was $33.42 \%$ by using DAT test $[17,18]$.

The results reported in (Table 1 and Table 2), which shows the seroprevalence of $T$. gondii seropositivity in aborted women were (58\%) by LAT and (34\%) for IgG antibodies and (26.6\%) by ELISA technique which they are significantly higher than seroprevalence of $T$. gondii seropositivity in control (normal birth) women in which they show (25\%) by LAT and (14\%) for IgG antibodies and (10\%) by ELISA technique. Such results were comparable to those obtained by Saeed (1998), she concluded in her results that $T$. gondii agglutinins prevalence in women suffering from abortion in Erbil city [19], also the same findings were indicated on aborted women in Mosul city, Duhok and Baghdad [20,21,17]. These results were in contrast with the observation of Akoijaam, et al., (2002), they found that no significant association between abortion and 
infection with T. gondli [22]. This variance may be explained by the presence of different source for distribution of the parasite in this locality and may be due to the difference in sanitation and hygienic way of living; or the difference may be due to the influence of climate on the survival of Toxoplasma oocysts in the environment, in addition different eating habits and differences in husbandry of domestic animals may affect exposure to infection [23].

The relationship of seropositive toxoplasmosis with residency was also studied. The higher seropositivity of T. gondii among aborted women in rural resident than those in urban resident, this result is in consistence with that of $[24,25]$. This finding is similar to that reported in Malaysia [26] and in Egypt [27]; in India [28] and in Erbil city [19] in which they observed that the disease is apparently more prevalent among rural aborted women than those living in urban community, but with no significant difference. The seroincidence variation between the two communities depends on the basis of poor standards of hygiene and lower socioeconomic status in rural area than in the urban, also rural women are more in contact with domestic and other animals than urban women. The pattern of risk factors and their relative importance are likely to vary appreciably across national boundaries in accordance with cultural patterns and climatic factors affecting the survival of oocysts [29]. This study revealed that there was significant relationship between soil contact and frequency of $T$. gondii seropositivity, while in normal birth women group show no significant difference. But in both groups frequency of $T$. gondii seropositivity using LAT and ELISA technique are higher in women who work on land or had contact with soil than that who without soil contact. This result is in consistence with that [30]. The association of cats and human toxoplasmosis is difficult to assess by epidemiological surveys because soil, not the cats, is the main culprit. Oocysts are not found on cat fur and often buried in soil along with cat faeces, and soil contact is universal and difficult to avoid. Contact with soil was identified as a risk factor for Toxoplasma infection in pregnancy in this study and in 2 of 3 previous studies that adjusted for confounders $[31,29]$.

\section{CONCLUSION}

The current investigation has concluded that the prevalence of Toxoplasma infection is highly prevalent among aborted women in Garmian district. Furthermore, the rate of Toxoplasma seropositivity was a highest in the second trimester of gestational period than first and third trimester by ELISA, while in LAT, the highest rate was in first trimester followed by second and third trimester. Moreover, pregnant women on soil contact had a higher rate of Toxoplasma infection than those not in contact with soil. Finally, frequency of Toxoplasma infection in rural resident was higher than urban resident.

\section{REFERENCES}

[1] J.S Remington, R. McLeod, P. Thulliez, G, Desmonts, G, "Toxoplasmosis, Infectious diseases of the fetus and newborn infant," In Remington, J.S. and Klein, J. $5^{\text {th }}$ (Ed.). W. B. Saunders, Philadelphia: 205, 2001.

[2] J. G. Montoya, O. Liesenfeld, “Toxoplasmosis,” Lancet.; 363 (9425): (2004).

[3] E. A. Shevkunova, L. A. Pohina, M. F. Nugumanova, “A case of chronic acquired toxoplasmosis with positive agents detectable in the blood,”. Med. Parasitol. (Mosk), 44: 235-238. 1975.

[4] D. M. Israelski, J. S. Remington, "Toxoplasmosis in the non-AIDS immunocompromised host," In Remington, J. S. and Swartz, M.N (ed.) Curr. Clin. Top. Infect. Dis., 13 Cambridge Mass. Black Well Scientific: 13: 322-356, 1993.

[5] R.G. Emerson, E. S. Milvenan, G. J. Elfenbein, R. Saral, “A plastic anemia developed seizure with bone marrow was successfully transplanted from a genotypical HL-A identical brother," Pediatrics, 67: 653, 1981.

[6] S. S. Gange, “Toxoplasmosis,” Primary care update. Obstet. Gynecol., 8(31): 122-126, 2001.

[7] D. T. John, J. W. A. Petri, “Markell and Voge's Medical parasitology,” $9^{\text {th }}$ ed. W. B. Saunders Elsevier, Philadelphia, U.S.A.: 160- 175, 2006.

[8] S. Martin, “Congenital toxoplasmosis,” Neonatal Netw, 20 (4):23, 2001.

[9] J. L. Jones, D. L. Hanson, M. S. Dworkin, "Surveillance for AIDS-defining opportunistic illnesses, 1992-1997,”. Mor Mortal Wkly Rep CDC. Surveill. Summ., 48(2): 1-22., 1999.

[10] R. Lopez, R. Contreras, L. Font, O. Vega, "Presence of antibodies against Toxoplasma gondii in adolescents," Rew. Latinoam. Microbiol., 34(1): 49-52. 1992.

[11] H. A. Feldman, "Epidemiology of Toxoplasma infection,” Epidemiol. Rev., 4: 204-213, 1982.

[12] B. H. Kean, "Clinical toxoplasmosis-50 years," Trans. Royal. Soc. Trop. Med. Hyg., , 66(4): 549-571, 1972.

[13] A. J. Al-Khariri, "Seropidemiological serological study of toxoplasmosis in Diyala province /Iraq,” M.Sc. Thesis, College of Education, University of Diyala, 2007.

[14] R. L. Al- Timimi, "Detection of toxoplasmosis among different groups of aborted women during gestational age of pregnancy," Diploma, Thesis, College of Medical and Health Technology, 2004

[15] F. A.M. Fatohi, "Detection of toxoplasmosis among different groups of populations in Mousl city by using IFAT and CFT," M.Sc. Thesis, College of Medicine, University of Mousl. 1985.

[16] S. A. Al-Attar, "Epidemiological study of toxoplasmosis in Kirkuk city,”. M.Sc. Thesis, College of Education. Tikrit University, 2000.

[17] A. N. Jasim, "Seroepidemiological Studies of Toxoplasmosis in Iraq: Evaluation of Serological Tests Used in Diagnosis," M.Sc. Thesis, College of Medicine, University of Baghdad, 1979.

[18] A. R. Al-Jubori, "Parasitological and immunological study of Toxoplasma gondii in Kirkuk province,” M.Sc. Thesis, College of Medicine, Baghdad University, 2005.

[19] V. D. Saeed, "Seroprevalence of toxoplasmosis in women with repeated abortion and in children with congenital blindness and mental retardation in Erbil,” M.Sc. Thesis. College of Education, University of Salahaddeen, 1998.

[20] F. H. O. Al-Khaffaf, "Isolation and seroepidemiological study of toxoplasmosis among women in child bearing age in Nineveh governorate," M.Sc. Thesis, College of Science, University of Mosul, 2001.

[21] B. D. Al-Doski, "Seroepidemiological study of toxoplasmosis among different groups of population in Duhok city by using latex agglutination test and indirect haemoagglutination test,” M.Sc. Thesis, College of Medicine, University of Duhok, 2000.

[22] B. Akoijaam, S. Shashikant, S. Kapoor, "Seroprevalence of Toxoplasma infection among primigravid women attending antenatal clinic at a secondary level hospital in North India,” $J$. 
Indian. Med. Asso., 100:591-601, 2002.

[23] D. Ashburn, "History and general epidemiology. Human toxoplasmosis," Volume 3. Edited by: Ho Yen DO, Joss AWL. Oxford University Press Chapter: 56-76, 1992.

[24] E. Sema, O. Pinar, T. Munevver, Y. Hasan, "Seroprevalence and risk factors for toxoplasm infection among pregnant women in Aydin province,” Turkey. BMC Public Health. (5): 66. ,2005.

[25] A. E. Ades, S. Parker, R. Gilbert, P. A. Tookey, T. Berry, M. Hjelm, A. H. Wilcox, D. Cubitt, C. S. Peckham, "Maternal prevalence of Toxoplasma antibody based on anonymous neonatal serosurvey: a geographical analysis'” Epidemiol. Infect., 110(1):127-133, 1993.

[26] S. Yazar, B. Altunoluk, A. Akman, I. Şahin, "Investigation of anti- Toxoplasma gondii antibodies in women during pregnancy,” Acta Parasitologica Turcica., 24(4):343-345, 2000.

[27] R. Attia, M. El- Zayat, H. Rizk, S. Motawea, "Toxoplasma IgG and IgM antibodies. A case control study,” J. Egypt. Soc. Parasitol., 25: 866-82, 1995.

[28] Y. R. Joshi, S. V. Yas, K. R. Josh, "Seroprevalence of Toxoplasmosis in Jodhpur, India,” J. Commun. Dis., 30 (1) :3237, 1998.

[29] G. Kapperud, P. A. Jenum, B. Stray-Pedersen, K.K. Melby, A. Eskild, J. Eng, "Risk factors for Toxoplasma gondii infection in pregnancy: results of a prospective case-control study in Norway,” Obstet. Gynecol. Surv., 52: 158-9, 1997.

[30] D. H. M. Joynson, "Epidemiology of toxoplasmosis in the U.K,” Scand. J. Infect. Dis., 84 (suppl.): 65, 1992.

[31] L. Baril, "Facteurs de risqué d acquisition de la toxoplasmose chez les femmes enceintes en 1995 (France). Risk factors for acquiring toxoplasmosis in pregnant women in 1995 (France)," Bulletin epidemiologique hebdomadaire. 16: 73-75, 1996. 